\title{
Impact of Safety-Engineered Devices on the Incidence of Occupational Blood and Body Fluid Exposures Among Healthcare Personnel in an Academic Facility, 2000-2014
}

\author{
Hajime Kanamori, MD, PhD, MPH; ${ }^{1,2}$ David J. Weber, MD, MPH; ${ }^{1,2,3}$ Lauren M. DiBiase, MS; $;^{1,2}$ \\ Karen L. Pitman, MSN, NP-C; ${ }^{3}$ Stephanie A. Consoli, RN; ${ }^{3}$ James Hill, MD; ${ }^{3,4}$ Emily E. Sickbert-Bennett, PhD, MS; ${ }^{1,2}$ \\ William A. Rutala, $\mathrm{PhD}, \mathrm{MPH}^{1,2,3}$
}

BACKGROUND. Legislative actions and advanced technologies, particularly dissemination of safety-engineered devices, have aided in protecting healthcare personnel from occupational blood and body fluid exposures (BBFE).

ов јестіле. To investigate the trends in BBFE among healthcare personnel over 15 years and the impact of safety-engineered devices on the incidence of percutaneous injuries as well as features of injuries associated with these devices.

MeтноDs. Retrospective cohort study at University of North Carolina Hospitals, a tertiary care academic facility. Data on BBFE in healthcare personnel were extracted from Occupational Health Service records (2000-2014). Exposures associated with safety-engineered and conventional devices were compared. Generalized linear models were applied to measure the annual incidence rate difference by exposure type over time.

RESUlts. A total of 4,300 BBFE, including 3,318 percutaneous injuries (77\%), were reported. The incidence rate for overall BBFE was significantly reduced during 2000-2014 (incidence rate difference, $1.72 ; P=.0003$ ). The incidence rate for percutaneous injuries was also dramatically reduced during 2001-2006 (incidence rate difference, 1.37; $P=.0079$ ) but was less changed during 2006-2014. Percutaneous injuries associated with safety-engineered devices accounted for $27 \%$ of all BBFE. BBFE was most commonly due to injecting through skin, placing intravenous catheters, and blood drawing.

CONCLUSIONS. Our study revealed significant overall reduction in BBFE and percutaneous injuries likely due in part to the impact of safetyengineered devices but also identified that a considerable proportion of percutaneous injuries is now associated with these devices. Additional prevention strategies are needed to further reduce percutaneous injuries and improve design of safety-engineered devices.

Infect Control Hosp Epidemiol 2016;37:497-504

Occupational blood and body fluid exposures (BBFE) to bloodborne pathogens (BBP) remain a serious public health concern. ${ }^{1}$ More than 50 pathogens have been documented to cause infection following BBFE to healthcare personnel (HCP). ${ }^{2}$ However, the most important $\mathrm{BBP}$ are hepatitis $\mathrm{B}$ virus (HBV), hepatitis $\mathrm{C}$ virus (HCV), and human immunodeficiency virus (HIV). ${ }^{2,3}$ Percutaneous injuries are the most frequent cause of occupationally acquired $\mathrm{HBV}, \mathrm{HCV}$, and HIV. It has been estimated that approximately 385,000 percutaneous injuries occurred annually among HCP in the United States in the period of 1997 to $1998 .{ }^{1,4}$ Direct costs of follow-up for HCP with percutaneous injuries have ranged from $\$ 500$ to $\$ 3,000$. $^{5,6}$
The Needlestick Safety and Prevention Act was enacted in the United States in 2001 and requires employers to provide HCP with safety-engineered devices and to document needlestick injuries. ${ }^{7}$ Legislative actions and advanced technologies, especially dissemination of safety-engineered devices, have aided in protecting HCP from occupational exposures to BBP. ${ }^{8,9}$ Currently, a variety of safety-engineered devices are commercially available, including more than 300 safety-engineered devices on the US market and more than 1,700 needlestick prevention devices with US patents. ${ }^{9}$ During an 11-year period (1995-2005), percutaneous injuries were estimated to be reduced by approximately $40 \%$ as a result of implementation in 2001 of the Needlestick Safety and

Affiliations: 1. Division of Infectious Diseases, University of North Carolina, Chapel Hill, North Carolina; 2. Hospital Epidemiology, University of North Carolina Health Care, Chapel Hill, North Carolina; 3. Occupational Health Service, University of North Carolina Health Care, Chapel Hill, North Carolina; 4. Department of Physical Medicine and Rehabilitation, University of North Carolina School of Medicine, Chapel Hill, North Carolina.

Received October 26, 2015; accepted January 5, 2016; electronically published February 9, 2016 
Prevention Act. ${ }^{10}$ However, injuries associated with safetyengineered devices now account for a substantial proportion of percutaneous injuries. ${ }^{11,12}$

Because few data are available on the overall reduction in BBFE since 2006, we undertook the following study whose goals were as follows: (1) to examine the trends in BBFE by nature of injury among HCP at University of North Carolina (UNC) Hospitals over the past 15 years and the relationship between exposures, sources positive for BBP, and infections in HCP; (2) to investigate the impact of safety-engineered devices on the incidence of percutaneous injuries; and (3) to analyze percutaneous injuries associated with safety-engineered and conventional devices by selected variables.

\section{METHODS}

This investigation was conducted at UNC Hospitals, an 853-bed tertiary care academic facility. Data on BBFE in HCP were extracted from Occupational Health Service records during the 15-year period (2000-2014) and were analyzed retrospectively. Data on sources positive for pathogens (HBV, HCV, HIV) and infections in HCP during 2000-2014 were also analyzed. Variables (occupational group, location, device type, nature of injury, activity, and personal protective equipment) that were entered into the electronic database during 2004-2014 were used for this study. All physicians in our Occupational Health Service database were residents or fellows. Attending physicians were excluded from this study since they were captured in another database. Safetyengineered devices included safety syringes $(1 \mathrm{~mL}$ and $\geq 3 \mathrm{~mL}$ ), introducers (central line, intravenous, and arterial), butterfly-winged steel protected needles, Mylar-coated capillary tubes, blunted sutures, insulin safety syringes, scalpel safety blades, vacutainer push button collection sets, safety needles, safety-holder blood culture devices, and retractable lancets. The mean number of full-time equivalents at UNC Hospitals per year was obtained from the UNC Hospitals Department of Human Resources. Annual rates of BBFE or percutaneous injuries were calculated as exposures or injuries per 100 full-time equivalent employees.

Statistical analysis was performed using SAS, version 9.3 (SAS Institute). We applied generalized linear models to measure the annual incidence rate difference (IRD) by exposure type over time. Statistical significance and confidence intervals were calculated by comparing these regression lines to a line with a zero slope. A value of $P<.05$ was considered statistically significant. This study was approved by the UNC Institutional Review Board.

\section{RES U L T S}

A total of 4,300 BBFE were reported during the 15-year period (2000-2014) and included 3,318 percutaneous injuries (77.2\%), 894 exposures to mucous membrane/non-intact skin $(20.8 \%)$, and 88 injuries due to bite/scratch $(2.0 \%)$.
The incidence rates for overall BBFE and percutaneous injuries were significantly reduced (IRD, $1.72, P=.0003$; and IRD, $1.65, P=.0002$, respectively) (Figure 1 ), but exposures to mucous membrane/non-intact skin and to bite/scratch remained unchanged. Furthermore, the incidence rate for percutaneous injuries was dramatically reduced during 2001-2006 (IRD, 1.37, $P=.0079$ ), compared with the rate reduction observed during 2006-2014 (IRD, 0.32, $P=.2383$ ). The annual frequency of percutaneous injuries accounted for most blood and body fluid exposures during the study period (relative mean [SD] percentage of BBFE: percutaneous injuries, $77.5 \%$ [3.6\%]; mucous membrane/non-intact skin, $20.5 \%$ [3.3\%]; bite/scratch, $2.0 \%$ [1.6\%]).

During 2004-2014, the 2,545 percutaneous injuries included 683 cases associated with safety-engineered devices $(26.8 \%)$ and 1,578 cases with conventional devices $(62.0 \%)$. There were 722 exposures to mucous membrane/non-intact skin, which included 61 cases associated with safetyengineered devices $(8.4 \%)$ and 81 cases with conventional devices $(11.2 \%)$, but 580 cases $(80.3 \%)$ were exposures of unknown mechanism. The incidence rate for percutaneous injuries associated with conventional devices was significantly

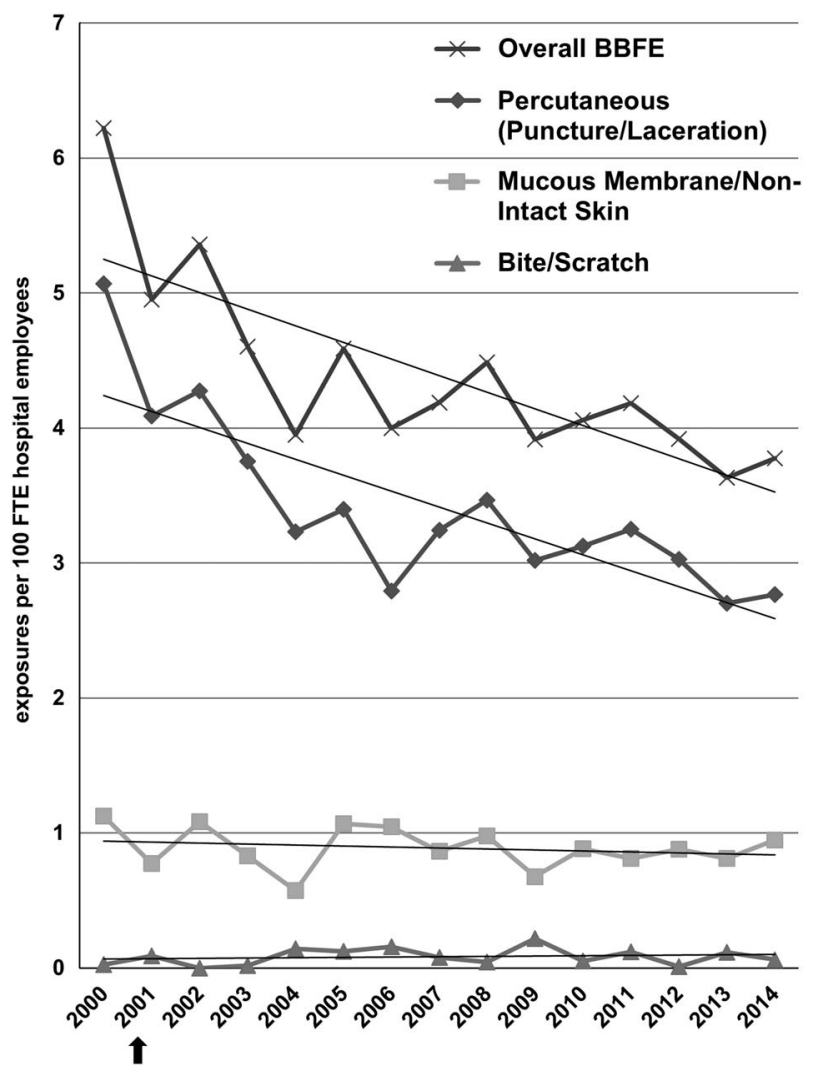

FIGURE 1. Incidences of blood and body fluid exposures (BBFE) by nature of injury among healthcare personnel, University of North Carolina Hospitals, 2000-2014. Arrow shows the year 2001 of the Needlestick Safety and Prevention Act. FTE, full-time equivalents. 
reduced (IRD, 0.65, $P=.003$ ) (Figure 2). Percutaneous injuries associated with safety-engineered devices increased (IRD, 0.22 , $P=.1065)$ over the study period, though the trend was not statistically significant. From 2004 to 2014, the relative proportion of percutaneous injuries associated with conventional devices decreased by $14 \%$, but that of percutaneous injuries associated with safety-engineered devices increased by $12 \%$ (relative mean [SD] percentage of percutaneous injuries: conventional devices, $62.5 \%$ [4.8\%]; safety-engineered devices, $26.4 \%$ [4.8\%]; unknown, $11.1 \%$ [2.0\%]). In 2014, of 272 percutaneous injuries reported at UNC Hospitals, 80 (29.4\%) were associated with safety-engineered devices.

BBFE associated with safety-engineered devices included cases with safety syringes $(n=227)$, introducers $(n=222)$, butterfly-winged steel protected needles $(n=122)$, insulin safety syringes $(n=66)$, blunted sutures $(n=47)$, scalpel safety blades $(n=38)$, vacutainer push button collection sets $(n=9)$, safety needles $(n=6)$, safety-holder blood culture devices $(n=4)$, Mylar-coated capillary tubes $(n=2)$, and retractable

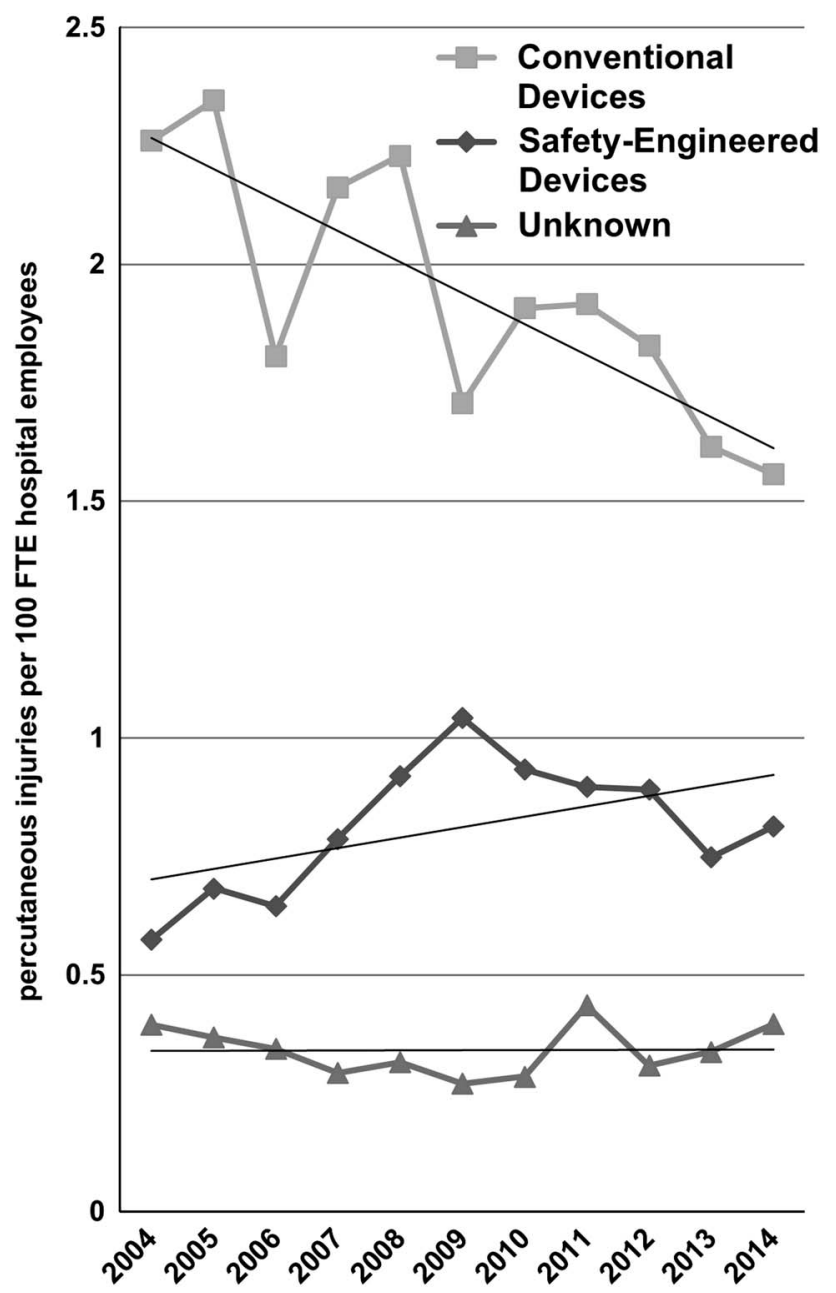

FIGURE 2. Incidences of percutaneous injuries associated with safety-engineered devices among healthcare personnel, University of North Carolina Hospitals, 2004-2014. FTE, full-time equivalents. lancets $(n=2)$. All types of safety-engineered devices that led to BBFE in this study were user-activated devices. Characteristics of BBFE associated with safety-engineered devices and conventional devices are summarized in Tables 1 and 2. BBFE associated with safety-engineered devices were more likely to occur in nurses and inpatient wards, whereas BBFE associated with conventional devices were in physicians and operating rooms. The frequency of percutaneous injuries associated with safety-engineered devices was $91.7 \%$, whereas that of splash to mucous membrane/non-intact skin was $8.2 \%$. The most frequent activities as a cause of BBFE associated with safetyengineered devices (selected devices per overall devices for each activity) were injecting through skin (safety syringe, $67.6 \%$; insulin safety syringe, $17.9 \%$ ), followed by starting an intravenous line (introducer, 94.2\%) and blood drawing (butterfly-winged steel protected needle, 74.1\%), whereas suturing (non-blunted suture, 99.4\%) was the most common percutaneous injury associated with conventional devices. Recapping (safety syringe, 60.4\%; insulin safety syringe, $24.8 \%$ ) was observed at a higher proportion of $13.6 \%$ in safetyengineered device-associated percutaneous injuries. A total of $5.5 \%$ of HCP who had BBFE associated with safety-engineered devices did not use gloves, whereas $92.6 \%$ of HCP used gloves when exposures occurred.

Of the 4,300 BBFE during the 15-year period, there were 603 sources positive for BBP (14.0\%), including 29 (0.7\%) for $\mathrm{HBV}, 397$ (9.2\%) for HCV, and 177 (4.1\%) for HIV, whereas there were 3,697 sources negative for a BBP $(86.0 \%)$. The incidence rate for overall BBP was significantly reduced (IRD, $0.45, P=.0011$ ) (Figure 3). Of BBP, the incidence for HCV and HIV was also significantly reduced (IRD, 0.31, $P=.0017$; and IRD, $0.13, P=.034$, respectively). However, the incidence for HBV was not significantly reduced (IRD, 0.021, $P=.1828$ ), although the incidence was low at less than 0.1 exposure per 100 full-time equivalents. The relative proportion of each BBP fluctuated annually over the study period (relative mean [SD] percentage of BBP: HBV, 5.0\% [3.4\%]; HCV, 66.0\% [6.3\%]; HIV, 29.1\% [5.9\%]). One healthcare provider contracted $\mathrm{HCV}$ infection $(0.25 \%$ in $\mathrm{HCV}$ exposures), although no infections with HBV or HIV occurred.

\section{I SCUSSION}

Data from the Exposure Prevention Information Network suggested that the estimated 385,000 percutaneous injuries among HCP in the United States during 1997-1998 can be reduced, as sharps-related injuries in nonsurgical hospital settings decreased $31.6 \%$ during 2001-2006. ${ }^{13}$ Our work extends previous work by evaluating the period from 2000 to 2014. We demonstrated significant overall reduction in BBFE and percutaneous injuries that may be in part due to the impact of safety-engineered devices and supported previous studies showing successful reduction of overall percutaneous injuries. ${ }^{11,14,15}$ Notably, safety-engineered devices worked well to decrease the incidence of percutaneous injuries from the 
TAв L 1. Blood and Body Fluid Exposures Associated With Safety-Engineered Devices and Conventional Devices by Occupational Group or Location, University of North Carolina Hospitals, 2004-2014

\begin{tabular}{|c|c|c|c|c|c|c|c|c|c|c|c|c|}
\hline \multirow[b]{2}{*}{ Variable } & \multicolumn{2}{|c|}{ Overall } & \multicolumn{10}{|c|}{ Selected devices } \\
\hline & $\begin{array}{l}\text { Safety- } \\
\text { engineered } \\
\text { devices }\end{array}$ & $\begin{array}{l}\text { Conventional } \\
\text { devices }\end{array}$ & $\begin{array}{l}\text { Safety } \\
\text { syringe }\end{array}$ & Syringe & $\begin{array}{c}\text { Scalpel } \\
\text { safety blade }\end{array}$ & $\begin{array}{l}\text { Scalpel } \\
\text { blade }\end{array}$ & $\begin{array}{l}\text { Butterfly-winged } \\
\text { protected needle }\end{array}$ & $\begin{array}{c}\text { Butterfly- } \\
\text { winged needle }\end{array}$ & $\begin{array}{l}\text { Insulin } \\
\text { safety } \\
\text { syringe }\end{array}$ & $\begin{array}{l}\text { Insulin } \\
\text { syringe }\end{array}$ & $\begin{array}{l}\text { Blunted } \\
\text { suture }\end{array}$ & $\begin{array}{c}\text { Non- } \\
\text { blunted } \\
\text { suture }\end{array}$ \\
\hline \multicolumn{13}{|l|}{ Occupation group } \\
\hline Nurse & 434 & 523 & 159 & 159 & 6 & 12 & 73 & 9 & 66 & 47 & 5 & 51 \\
\hline Medical doctor & 196 & 888 & 54 & 154 & 26 & 90 & 1 & 3 & 0 & 1 & 36 & 500 \\
\hline Laboratory technician & 45 & 53 & 0 & 3 & 2 & 2 & 38 & 2 & 0 & 0 & 0 & 0 \\
\hline Surgical technician & 19 & 117 & 5 & 15 & 4 & 15 & 1 & 0 & 0 & 0 & 4 & 61 \\
\hline Environmental services & 6 & 15 & 1 & 7 & 0 & 0 & 1 & 0 & 0 & 0 & 0 & 1 \\
\hline Nurse anesthetist & 6 & 7 & 1 & 4 & 0 & 0 & 1 & 0 & 0 & 0 & 0 & 0 \\
\hline Other & 39 & 113 & 7 & 25 & 0 & 6 & 7 & 2 & 0 & 3 & 2 & 16 \\
\hline Total & 745 & 1716 & 227 & 367 & 38 & 125 & 122 & 16 & 66 & 51 & 47 & 629 \\
\hline \multicolumn{13}{|l|}{ Location } \\
\hline Inpatient ward & 226 & 201 & 94 & 54 & 2 & 1 & 32 & 1 & 44 & 15 & 1 & 10 \\
\hline Intensive care unit & 126 & 176 & 42 & 56 & 3 & 14 & 15 & 1 & 17 & 2 & 3 & 27 \\
\hline Operating room & 93 & 645 & 28 & 65 & 14 & 49 & 3 & 1 & 0 & 1 & 23 & 410 \\
\hline Outpatient & 58 & 100 & 30 & 40 & 2 & 0 & 6 & 1 & 2 & 0 & 2 & 30 \\
\hline Emergency room & 56 & 67 & 9 & 24 & 1 & 2 & 19 & 0 & 0 & 2 & 0 & 20 \\
\hline Radiology/procedures & 33 & 39 & 7 & 23 & 2 & 5 & 2 & 0 & 0 & 0 & 2 & 4 \\
\hline Laboratory & 17 & 48 & 0 & 4 & 10 & 13 & 6 & 0 & 0 & 0 & 0 & 2 \\
\hline $\begin{array}{l}\text { Post-anesthesia care } \\
\text { unit }\end{array}$ & 9 & 11 & 2 & 6 & 0 & 0 & 2 & 1 & 0 & 0 & 1 & 2 \\
\hline Labor \& delivery & 8 & 57 & 3 & 9 & 0 & 4 & 3 & 1 & 0 & 0 & 1 & 33 \\
\hline Other & 119 & 372 & 12 & 86 & 4 & 37 & 34 & 10 & 3 & 31 & 14 & 91 \\
\hline Total & 745 & 1716 & 227 & 367 & 38 & 125 & 122 & 16 & 66 & 51 & 47 & 629 \\
\hline
\end{tabular}


TAв LE 2. Blood and Body Fluid Exposures Associated With Safety-Engineered Devices and Conventional Devices by Nature of Injury or Activity, University of North Carolina Hospitals, 2004-2014

\begin{tabular}{|c|c|c|c|c|c|c|c|c|c|c|c|c|}
\hline & \multicolumn{2}{|c|}{ Overall } & \multicolumn{10}{|c|}{ Selected devices } \\
\hline & $\begin{array}{l}\text { Safety- } \\
\text { engineered } \\
\text { devices }\end{array}$ & $\begin{array}{l}\text { Conventional } \\
\text { devices }\end{array}$ & $\begin{array}{l}\text { Safety } \\
\text { syringe }\end{array}$ & Syringe & $\begin{array}{c}\text { Scalpel } \\
\text { safety } \\
\text { blade }\end{array}$ & $\begin{array}{l}\text { Scalpel } \\
\text { blade }\end{array}$ & $\begin{array}{l}\text { Butterfly-winged } \\
\text { protected needle }\end{array}$ & $\begin{array}{c}\text { Butterfly- } \\
\text { winged } \\
\text { needle }\end{array}$ & $\begin{array}{l}\text { Insulin } \\
\text { safety } \\
\text { syringe }\end{array}$ & $\begin{array}{l}\text { Insulin } \\
\text { syringe }\end{array}$ & $\begin{array}{c}\text { Blunted } \\
\text { suture }\end{array}$ & $\begin{array}{c}\text { Non- } \\
\text { blunted } \\
\text { suture }\end{array}$ \\
\hline \multicolumn{13}{|l|}{ Nature of injuries } \\
\hline $\begin{array}{l}\text { Percutaneous injuries } \\
\quad \text { (puncture/laceration) }\end{array}$ & 683 & 1578 & 215 & 338 & 37 & 124 & 118 & 14 & 65 & 51 & 47 & 627 \\
\hline $\begin{array}{l}\text { Splash to mucous membrane/ } \\
\text { non-intact skin }\end{array}$ & 61 & 81 & 12 & 28 & 1 & 1 & 4 & 1 & 0 & 0 & 0 & 1 \\
\hline Other & 1 & 57 & 0 & 1 & 0 & 0 & 0 & 1 & 1 & 0 & 0 & 1 \\
\hline Total & 745 & 1716 & 227 & 367 & 38 & 125 & 122 & 16 & 66 & 51 & 47 & 629 \\
\hline \multicolumn{13}{|l|}{ Activity } \\
\hline Injecting through skin & 145 & 241 & 98 & 153 & 0 & 2 & 1 & 0 & 26 & 28 & 0 & 2 \\
\hline Starting intravenous injection & 139 & 17 & 0 & 7 & 0 & 2 & 8 & 1 & 0 & 0 & 0 & 1 \\
\hline Blood drawing & 112 & 131 & 12 & 32 & 0 & 0 & 83 & 11 & 0 & 0 & 0 & 0 \\
\hline Recapping & 101 & 72 & 61 & 33 & 1 & 0 & 5 & 1 & 25 & 9 & 0 & 0 \\
\hline Disposal at sharps container & 62 & 100 & 17 & 47 & 0 & 0 & 16 & 1 & 13 & 12 & 0 & 6 \\
\hline Suturing & 38 & 481 & 0 & 0 & 0 & 0 & & 0 & 0 & 0 & 35 & 478 \\
\hline Inappropriate location & 35 & 62 & 20 & 13 & 2 & 11 & 2 & 0 & 1 & 1 & 1 & 19 \\
\hline Cleaning up/sorting & 35 & 113 & 6 & 27 & 4 & 11 & 3 & 0 & 0 & 0 & 6 & 30 \\
\hline Passing instrument & 20 & 104 & 8 & 11 & 6 & 9 & 2 & 1 & 0 & 0 & 3 & 62 \\
\hline Cutting/slicing & 22 & 108 & 0 & 0 & 22 & 74 & 0 & 0 & 0 & 0 & 0 & 3 \\
\hline Patient care procedure & 17 & 103 & 2 & 17 & 0 & 6 & 0 & 1 & 0 & 1 & 0 & 1 \\
\hline Surgical device manipulation & 4 & 45 & 0 & 2 & 1 & 5 & 0 & 0 & 0 & 0 & 1 & 11 \\
\hline $\begin{array}{l}\text { Collecting waste (pulling trash, } \\
\text { transporting trash) }\end{array}$ & 2 & 13 & 1 & 3 & 0 & 0 & 0 & 0 & 0 & 0 & 0 & 1 \\
\hline Shaving & 2 & 4 & 0 & 0 & 1 & 1 & 0 & 0 & 0 & 0 & 0 & 0 \\
\hline Holding retractor & 1 & 14 & 0 & 2 & 1 & 0 & 0 & 0 & 0 & 0 & 0 & 6 \\
\hline Laboratory procedure & 2 & 18 & 0 & 3 & 0 & 1 & 1 & 0 & 0 & 0 & 0 & 0 \\
\hline Sawing & 1 & 8 & 0 & 0 & 0 & 0 & 0 & 0 & 0 & 0 & 1 & 4 \\
\hline Cauterizing & 0 & 7 & 0 & 0 & 0 & 0 & 0 & 0 & 0 & 0 & 0 & 0 \\
\hline Dental procedure & 0 & 7 & 0 & 1 & 0 & 0 & 0 & 0 & & 0 & 0 & 0 \\
\hline Drilling & 0 & 10 & 0 & 0 & 0 & 0 & 0 & 0 & 0 & 0 & 0 & 0 \\
\hline Emptying body fluid & 0 & 8 & 0 & 2 & 0 & 0 & 0 & 0 & 0 & 0 & 0 & 0 \\
\hline Inserting drain & 0 & 3 & 0 & 0 & 0 & 1 & 0 & 0 & 0 & 0 & 0 & 0 \\
\hline Suctioning & 0 & 1 & 0 & 0 & 0 & 0 & 0 & 0 & 0 & 0 & 0 & 1 \\
\hline Wound care & 1 & 9 & 0 & 3 & 0 & 0 & 0 & 0 & 0 & 0 & 0 & 0 \\
\hline Other & 6 & 37 & 2 & 11 & 0 & 2 & 1 & 0 & 1 & 0 & 0 & 4 \\
\hline Total & 745 & 1716 & 227 & 367 & 38 & 125 & 122 & 16 & 66 & 51 & 47 & 629 \\
\hline
\end{tabular}




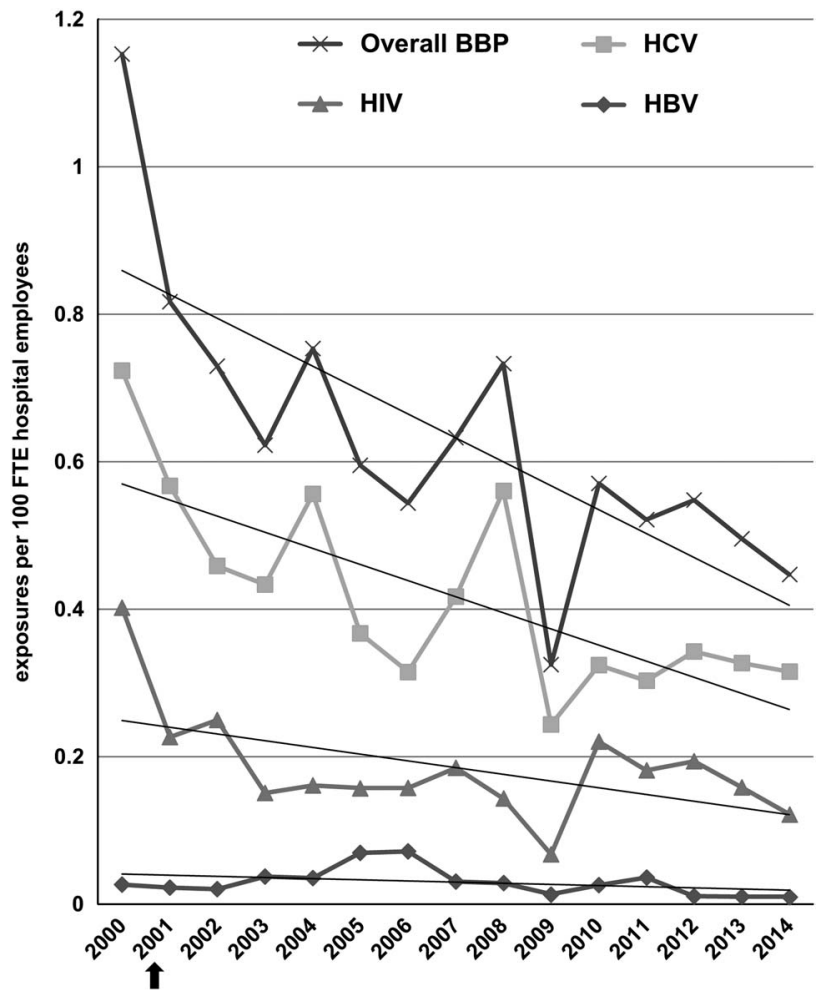

FIGURE 3. Incidences of blood and body fluid exposures by source positive for bloodborne pathogens (BBP) among healthcare personnel, University of North Carolina Hospitals, 2000-2014. Arrow shows the year 2001 of the Needlestick Safety and Prevention Act. FTE, full-time equivalents. HBV, hepatitis B virus; $\mathrm{HCV}$, hepatitis $\mathrm{C}$ virus; HIV, human immunodeficiency virus.

2001 Act to 2006, but this positive impact of safety-engineered devices stabilized after 2006. Therefore, we need new interventions aimed at further reducing the injuries among HCP in addition to using safety-engineered devices. Through a multidisciplinary Needlestick Prevention Working Group, UNC Hospitals is working toward eliminating needlestick injuries via yearly education, placement of needle disposal devices in every room, improved practices (no passing sharp instruments directly person-to-person in the operating room), double-gloving for high-risk surgical procedures that might lead to damage to gloves (eg, orthopedic surgery), use of needleless connectors for intravenous lines, and availability of blunted suture needles in the operating room. Unfortunately, our data demonstrated that many injuries in the operating room still result from suture needles. Although blunted suture needles are available, they cannot be used in all cases (eg, skin sutures) and many surgeons choose not to use them even when indicated. A previous article described substantial decreases in percutaneous injuries after implementation of safetyengineered devices, ranging $22 \%-100 \% .{ }^{14}$ According to a recent meta-analysis, training, safety-engineered devices, and training combined with safety-engineered devices reduced the rate of needlestick injuries by $34 \%, 49 \%$, and $62 \%$, respectively. ${ }^{15}$ Our study identified that a considerable proportion of percutaneous injuries are now associated with safety-engineered devices. Further, the frequency of percutaneous injuries associated with safety-engineered devices is now similar to the level of overall exposures to mucous membrane/ non-intact skin, suggesting the necessity for improving measures to prevent exposures from the use of HCP-activated safety-engineered devices as well as conventional devices. A retrospective review of percutaneous injuries from hollow bore safety-engineered devices in the United States described that approximately $75 \%$ of exposures occurred when the safety function was not appropriately activated. ${ }^{12}$ In a French multicenter study, the use of passive safety-engineered devices was related to the lowest needlestick injuries rate. ${ }^{11}$ Percutaneous injuries associated with safety-engineered devices may be caused by poor knowledge and instruction, improper use of devices by HCP, mechanical failure of safety function, and incomplete activation of the safety-engineered devices, ${ }^{11,12,16}$ suggesting that proper training is required since engineering controls alone would not solve this issue.

In our study, there was also a concern for safety-engineered device-associated exposures to mucous membrane/non-intact skin as well as that most device types resulting in exposures to mucous membrane/non-intact skin were unknown. Experimental studies have described that macroscopic and microscopic blood splatter from retractable intravenous devices or spatter contamination due to manually activated safety-engineered devices after syringe discharge and safety activation can occur, although the risk for acquiring BBP from surface contamination with blood and body fluids in healthcare settings is not well known. ${ }^{17-19}$ More than $90 \%$ of HCP in our study used gloves when exposures occurred, but the minority of BBFE was also observed owing to failure to wear gloves and nonadherence to personal protective equipment. Proper use of personal protective equipment should be maintained since splashing may not be detected. Safe work practices (eg, keeping contaminated hands away from face; positioning patients) as well as rigorous compliance with standard precautions are necessary to protect mucous membranes/non-intact skin from BBFE. ${ }^{20}$

Our data showed that 3 major activities of safety-engineered device-associated percutaneous injuries were injecting through skin, placing intravenous catheters, and blood drawing, accounting for half of all cases in this study. Recapping was also found even when using safety-engineered devices. When safetyengineered devices are newly adopted or percutaneous injuries associated with specific type of safety-engineered devices are found in healthcare facilities, enhanced education and training program should focus on appropriate use of safety-engineered devices as well as implementation of rigorous standard precautions and other prevention measures against percutaneous injuries (eg, double-gloving). Because BBFE remain a major problem in operating rooms, continual education and training of surgeons, introduction of passive safety-engineered devices whenever possible, and further development of safetyengineered devices in surgical fields are needed. Unfortunately, 
safety-engineered devices cannot be used in all circumstances (eg, skin incisions); therefore, strict adherence to proper management of sharp instruments must continue to be taught.

The incidence rate for BBFE to overall BBP was also reduced in our study period. Importantly, the significant reduction in BBFE to HCV among HCP should be noted since pre- or postexposure prophylaxis against $\mathrm{HCV}$ infections is currently unavailable. Our data demonstrated that a reduction in the incidence of exposure of our employees to a BBP via a sharps injury was due to the decrease in the incidence of such injuries, not to a change in the frequency of BBP among source patients. The risk of exposures to BBP can be reduced by thorough adherence to the administrative, engineering, and work practice controls.

There are several limitations for this study. First, our results at single tertiary care academic facility may not be generalizable but have been obtained on the basis of longitudinal trends. Second, we captured only physicians who were residents or fellows, although this group had 1,084 BBFE associated with safety-engineered devices and conventional devices during 2004-2014. However, at any given time there were many more residents/fellows providing direct patient care than attending physicians. These trainees might have had a higher rate of injuries than more experienced physicians. Also, the absolute number of injuries among physicians is lower than the actual number since attending physicians were not included in the database. Third, the number of BBFE as a numerator may be affected by underreporting, but our reporting system has been maintained in a consistent manner during the study period. We evaluated the annual incidence rates of BBFE by using full-time equivalents as denominators, similar to the methods used by other authors, ${ }^{6,15}$ but non-nursing occupation groups may have a higher rate of exposures. ${ }^{1}$ Even if the limitations stated above are considered, our data demonstrated that significant reductions in BBFE among HCP after introduction of safetyengineered devices occurred over the past 15 years. Additional efforts are needed to further reduce percutaneous injuries and improve the design of safety-engineered devices.

\section{ACKNOWLEDGMENTS}

We thank David Williams for his assistance in data collection.

Financial support. UNC Health Care; and Japan Society for the Promotion of Science (JSPS) Postdoctoral Fellowship for Research Abroad (to H.K.).

Potential conflicts of interest. All authors report no conflicts of interest relevant to this article.

Address correspondence to Hajime Kanamori, MD, PhD, MPH, Hospital Epidemiology, UNC Health Care, 1001 West Wing CB \#7600, 101 Manning Dr, Chapel Hill, NC 27514 (kanamori@med.unc.edu).

\section{REFERENCES}

1. Centers for Disease Control and Prevention (CDC). Workbook for designing, implementing and evaluating a sharps injury prevention program. CDC website. http://www.cdc.gov/sharps safety/pdf/sharpsworkbook_2008.pdf. Accessed July 19, 2015.
2. Tarantola A, Abiteboul D, Rachline A. Infection risks following accidental exposure to blood or body fluids in health care workers: a review of pathogens transmitted in published cases. Am J Infect Control 2006;34:367-375.

3. Deuffic-Burban S, Delarocque-Astagneau E, Abiteboul D, Bouvet E, Yazdanpanah Y. Blood-borne viruses in health care workers: prevention and management. J Clin Virol 2011;52:4-10.

4. Panlilio AL, Orelien JG, Srivastava PU, et al; NaSH Surveillance Group; EPINet Data Sharing Network. Estimate of the annual number of percutaneous injuries among hospital-based healthcare workers in the United States, 1997-1998. Infect Control Hosp Epidemiol 2004;25:556-562.

5. US General Accounting Office (GAO). Occupational safety: selected cost and benefit implications of needlestick prevention devices for hospitals, GAO-01-60R. GAO website. http://www. gao.gov/new.items/d0160r.pdf. Published November 17, 2000.

6. Phillips EK, Conaway M, Parker G, Perry J, Jagger J. Issues in understanding the impact of the Needlestick Safety and Prevention Act on hospital sharps injuries. Infect Control Hosp Epidemiol 2013;34:935-939.

7. Needlestick Safety and Prevention Act of 2000, Pub L No. 106430, 114 Stat 190. National Institutes of Health website. https:// history.nih.gov/research/downloads/PL106-430.pdf. Published November 6, 2000.

8. Jagger J, Perry J, Gomaa A, Phillips EK. The impact of US policies to protect healthcare workers from bloodborne pathogens: the critical role of safety-engineered devices. I Infect Public Health 2008;1:62-71.

9. Jagger J, Perry J. Safety-engineered devices in 2012: the critical role of healthcare workers in device selection. Infect Control Hosp Epidemiol 2013;34:615-618.

10. Phillips EK, Conaway MR, Jagger JC. Percutaneous injuries before and after the Needlestick Safety and Prevention Act. N Engl J Med 2012;366:670-671.

11. Tosini W, Ciotti C, Goyer F, et al. Needlestick injury rates according to different types of safety-engineered devices: results of a French multicenter study. Infect Control Hosp Epidemiol 2010;31:402-407.

12. Black L. Chinks in the armor: percutaneous injuries from hollow bore safety-engineered sharps devices. Am J Infect Control 2013;41:427-432.

13. The National Institute for Occupational Safety and Health (NIOSH). Stop Sticks Campaign. NIOSH website. http://www.cdc. gov/niosh/stopsticks/sharpsinjuries.html. Accessed December 4, 2015.

14. Tuma S, Sepkowitz KA. Efficacy of safety-engineered device implementation in the prevention of percutaneous injuries: a review of published studies. Clin Infect Dis 2006;42:1159-1170.

15. Tarigan LH, Cifuentes M, Quinn M, Kriebel D. Prevention of needle-stick injuries in healthcare facilities: a meta-analysis. Infect Control Hosp Epidemiol 2015;36:823-829.

16. Floret N, Ali-Brandmeyer O, L'Hériteau F, et al; Working Group AES-RAISIN. Sharp decrease of reported occupational blood and body fluid exposures in French hospitals, 2003-2012: results of the French National Network Survey, AES-RAISIN. Infect Control Hosp Epidemiol 2015;36:963-968.

17. Haiduven D, Applegarth S, Shroff M. An experimental method for detecting blood splatter from retractable phlebotomy and intravascular devices. Am J Infect Control 2009;37:127-130. 
18. Ansari A, Ramaiah P, Collazo L, Salihu HM, Haiduven D. Comparison of visual versus microscopic methods to detect blood splatter from an intravascular catheter with engineered sharps injury protection. Infect Control Hosp Epidemiol 2013;34:1174-1180.

19. Roff M, Basu S, Adisesh A. Do active safety-needle devices cause spatter contamination? J Hosp Infect 2014;86:221-223.
20. Siegel JD, Rhinehart E, Jackson M, Chiarello L, Healthcare Infection Control Practices Advisory Committee (HICPAC). 2007 Guideline for isolation precautions: preventing transmission of infectious agents in healthcare settings. HICPAC website. http://www.cdc.gov/hicpac/pdf/isolation/Isolation2007. pdf. Accessed July 19, 2015. 